\title{
Poor quality of obesity care in the US
}

Many opportunities to screen for, diagnose and treat obesity are being missed in the US, says Jun Ma, of the Palo Alto Medical Foundation Research Institute, California, and colleagues. These researchers examined obesity screening, diagnosis and counseling for adults in the US, cared for in office-based, private practices, and assessed whether these measures were associated with patients' and providers' factors. The team analyzed data on 696 million visits from the 2005 and 2006 National Ambulatory Medical Care Surveys, considered the best source of data on use and provision of health care in office-based, ambulatory settings throughout the US.

"BMI and obesity status could not be determined in half of office visits because of missing height or weight data," notes Ma. Of visits by patients with sufficient data to indicate clinical obesity (BMI $\geq 30 \mathrm{~kg} / \mathrm{m}^{2}$ ), $70 \%$ were not diagnosed and $63 \%$ received no counseling for lifestyle changes recommended for treatment of obesity (diet, exercise or weight reduction). Rates of diagnosis and provision to treat were low even for obese patients who presented with obesityrelated comorbidities. Characteristics of patients and providers had very little effect on the low rates of screening, diagnosis, and treatment of obesity.

"Optimal health care for the [large] numbers of Americans with [obesity and related] chronic diseases requires both a change in the conceptualization of health care models and in the implementation of health care itself," Ma concludes.

\section{Lisa Richards}

Original article Ma, J. et al. Adult obesity and officebased quality of care in the United States. Obesity 17 , 1077-1085 (2009). 